\title{
El precio de la usabilidad
}

\section{Por Antonio Moreno Muñoz}

POR CADA EURO QUE UNA COMPAÑÍA INVIERTE en el desarrollo de la usabilidad de un producto, ésta recibe entre diez y cien euros de beneficio. $Y$ no solamente, además se aumenta la satisfacción del usuario y se garantiza la supervivencia del producto y la continuidad del negocio. Esta es la idea más impactante de la Dra. Claire Marie Karat, y que aquí nos sirve de presentación, que planea por los estudios acerca de los costes de implantación de la usabilidad que ha realizado esta especialista de IBM.

\section{Pero, ¿qué es la usabilidad?}

De estos trabajos se deduce además que el dinero gastado en subsanar un problema de usabilidad en la etapa de diseño, se multiplicará por diez al menos si la solución es buscada en la etapa de desarrollo. Y por diez más si se trata posteriormente a su distribución.

\section{«El dinero gastado en subsanar un proble- ma de usabilidad en la etapa de diseño, se multiplicará por diez al menos si la solu- ción es buscada en la etapa de desarrollo. Y por diez más si se trata posteriormente a su distribución»}

Pero detengámonos y tratemos de acercarnos al concepto de usabi- lidad. Pues aunque algunos se den por satisfechos con traducir "usability" por facilidad de uso, el término parece contemplar alguna idea más: posibilidades de uso, potencial... Y siempre dentro de un contexto específico, aparecen objetivos muy concretos como el rendimiento, la efectividad o la satisfacción del usuario.

Aunque a corto plazo parece fácil compensar la dificultad de manejo de un producto con una buena campaña publicitaria, a medio y a largo plazo, ocupar un lugar en el mercado puede conseguirse de manera más económica si desde el principio elegimos el diseño centrado en el usuario, adoptando un ciclo de vida en estrella como estrategia central de evaluación. 
http://www-3.ibm.com/ibm/easy/ eou_ext.nsf/Publish/23

http://www.sidar.org/visitable/quee s/usab.htm

\section{La importancia de la usabilidad}

En un trabajo de F. Marcos Sanz, Enrique J. Gómez y Francisco del Pozo se revisan diversos estudios en los que se ilustra como la usabilidad incide de manera real y concreta en la relación coste-beneficio del desarrollo de un sistema de información. Han sido establecidos incluso modelos de análisis coste-beneficio (Jacob Nielsen, 1993). Aunque para los sistemas comerciales el incremento de ventas o la reducción del precio final parecen determinantes, los sistemas internos, desarrollados dentro de la misma empresa encuentran sus beneficios en el aumento de productividad, en la reducción de gastos en formación y en la seguridad y satisfacción de sus empleados. Puede ser descriptivo subrayar algunas estadísticas de este trabajo:

- La interfaz de usuario es aproximadamente el $60 \%$ de las lí- neas de código del total de un sistema de información interactivo.

-Una interfaz de usuario gráfica supone como mínimo el $29 \%$ del presupuesto de desarrollo del sistema.

-El $80 \%$ por ciento de los costes del ciclo de vida del software se produce después de que el producto haya sido distribuido, y el $80 \%$ por ciento de este coste se debe a requisitos no cumplidos (sólo el $20 \%$ por ciento es debido a errores o falta de fiabilidad).

http://www.tid.es/presencia/boletin /bolet10/art007.htm

\section{Soluciones aquí y ahora}

Existe un catálogo importante de estrategias para la ingeniería de uso. La elección acertada dependerá de la situación real de cada proyecto. Aunque se viene desarrollando una labor muy importante en organizaciones como la Asociación española de ergonomía, el Seminario de iniciativas sobre discapacidad y accesibilidad en la red o la Asociación de interacción persona-ordenador, el panorama de la industria en nuestro país es de una bisoñez declarada y su desarrollo fundamentalmente vinculado al boom de internet. Presentándose los estudios de usabilidad como un valor añadido en el desarrollo de la presencia web o ligado a la estrategia publicitaria que cada vez es más frecuente en la red.

http://www.prevencionintegral.co m/Default.asp?http://www.prevenc ionintegral.com/AEE/

http://griho.udl.es:8080/aipo/

http://www.sidar.org

http://www.cs.umd.edw/ zzj/Cost.html

http://www.expansiondirecto.com/ edicion/componentes/noticia/Versi onImprimirExp_cmp/0,3240,3360 9,00.html

\section{Bibliografía}

Nielsen, Jakob. "Is Usability Engineering really worth it?". En: IEEE Software, 1993, Noviembre, pp. 90-92.

\section{Antonio Moreno Muñoz}

ellmomua@uco.es

http://www.uco.es/ ellmomua/ergonomial

Universidad de Córdoba 